\title{
The DASH Diet and Cardiometabolic Health and Chronic Kidney Disease: A Narrative Review of the Evidence in East Asian Countries
}

\author{
Yazhen Song ${ }^{1}$, Andrea J. Lobene ${ }^{2,3, *}$, Yanfang Wang ${ }^{1}$ and Kathleen M. Hill Gallant ${ }^{2,4}$ \\ 1 Peking University Clinical Research Institute, Beijing 100191, China; sophiasong0829@gmail.com (Y.S.); \\ yanfang1225@gmail.com (Y.W.) \\ 2 Department of Nutrition Science, Purdue University, West Lafayette, IN 47907, USA; hillkm@umn.edu \\ 3 Department of Kinesiology and Applied Physiology, University of Delaware, Newark, DE 19713, USA \\ 4 Department of Food Science and Nutrition, University of Minnesota, St. Paul, MN 55108, USA \\ * Correspondence: alobene@udel.edu
}

check for

updates

Citation: Song, Y.; Lobene, A.J.; Wang, Y.; Hill Gallant, K.M. The DASH Diet and Cardiometabolic Health and Chronic Kidney Disease: A Narrative Review of the Evidence in East Asian Countries. Nutrients 2021, 13, 984. https://doi.org/ $10.3390 /$ nu13030984

Academic Editors: Pramod Khosla and Shannon L. Lennon

Received: 17 January 2021

Accepted: 16 March 2021

Published: 18 March 2021

Publisher's Note: MDPI stays neutral with regard to jurisdictional claims in published maps and institutional affiliations.

Copyright: (C) 2021 by the authors. Licensee MDPI, Basel, Switzerland. This article is an open access article distributed under the terms and conditions of the Creative Commons Attribution (CC BY) license (https:/ / creativecommons.org/licenses/by/ $4.0 /)$.

\begin{abstract}
The rising incidence of cardiometabolic diseases and chronic kidney disease (CKD) is a leading public health problem in East Asia. Diet is an important modifiable risk factor; thus, adopting a healthy diet such as the Dietary Approaches to Stop Hypertension (DASH) diet may help combat these chronic diseases. The DASH diet was originally developed in a U.S. population, and East Asia is demographically and culturally different from the U.S. Therefore, it is important to examine the evidence regarding the DASH diet and chronic disease in this unique population. This narrative review summarizes the evidence on the DASH diet and cardiometabolic health and CKD in East Asia. Culturally-modified DASH diets have been developed in some East Asian countries. Studies suggest the DASH diet is effective at lowering blood pressure in this population, though the long-term benefits remain unclear. Evidence also suggests the DASH diet may reduce the risk of type 2 diabetes and metabolic syndrome. Further research indicates the DASH diet and its components may reduce CKD risk. However, recommending the DASH diet in those who already have CKD is controversial, as it conflicts with current CKD dietary guidelines, especially in advanced CKD. Notably, current intakes in the general population differ from the DASH dietary pattern, suggesting public health efforts would be needed to encourage adoption of the DASH diet.
\end{abstract}

Keywords: DASH diet; cardiovascular disease; type 2 diabetes; chronic kidney disease; cardiometabolic health; East Asia; China; Japan; South Korea

\section{Introduction}

The increasing incidence of chronic diseases like cardiovascular disease (CVD), diabetes, and chronic kidney disease (CKD) has become a significant health problem in Asia [1,2]. In China, CVD has become the top cause of death, with approximately 290 million prevalent cases during 2016 [3]. East Asian countries also have a high prevalence of type 2 diabetes (China 9.6\%, Taiwan 9.8\%, Japan 7.6\%, South Korea 8.9\%) with China and Japan among the top 10 countries globally for number of people with type 2 diabetes [4]. Among East Asian patients with hypertension and type 2 diabetes, $40-70 \%$ have micro or macroalbuminuria, which is an indicator of kidney damage and risk factor for CVD mortality [5]. Hypertension and diabetes are the most common underlying etiologies for CKD [6], and patients often present with two or more of these conditions together. Indeed, in China, the prevalence of hypertension in CKD patients is 78.4\% [7]. Both high-income and middle-income countries in East Asia face the challenge of increasing CKD prevalence, partially driven by an aging population [8], which is especially challenging in developing countries [9]. In China, the largest developing country in the world, the prevalence of CKD is $10.8 \%$ or about 119.5 million people based on the results of a nationally representative survey [10]. However, only $12.5 \%$ of those with CKD in China are aware of 
their condition $[10,11]$. Given these data, it is clear that developing interventions to target blood pressure (BP) regulation and blood glucose control are important for preventing chronic diseases such as CVD, type 2 diabetes, and CKD. Dietary factors are important contributors to the incidence of these chronic diseases. The new Global Burden of Disease Study 1990-2017 found that East Asia has the highest age-standardized rates of diet-related CVD deaths and disability-adjusted life years (DALYs) around the world [12]. This same study found that a high intake of sodium was the leading dietary risk factor for deaths and DALYs in East Asia, and other dietary risk factors in China included low intake of whole grains and fruit in China [12]. Indeed, high BP caused by salt consumption is shown to be a major contributor to CVD in China [13], South Korea [14], and Japan [15], as well as other East Asian countries [16]. These findings suggest that improving dietary intakes in East Asian countries could be an important strategy for combating chronic disease.

When considering dietary recommendations for reducing chronic disease incidence and risk in East Asia, one intervention to consider is the Dietary Approaches to Stop Hypertension (DASH) diet. The original DASH trials were conducted in the United States $[17,18]$, and since then the DASH diet and its relationship to chronic disease has been studied all over the world with largely positive results [19-23]. However, each region and country has unique demographic and cultural characteristics that may impact the efficacy and effectiveness of the DASH diet. For example, East Asians develop type 2 diabetes at a younger age and a lower BMI compared to Caucasians, and these patients are more likely to experience a stroke or develop renal complications [24]. In addition, East Asians have different beliefs and attitudes about healthy eating compared to the U.S. [25] Thus, it is important to review the evidence within specific cultural or regional populations. While studies have examined the DASH diet and its relationship to cardiometabolic health and CKD in East Asia, the evidence has not been reviewed or synthesized previously. Thus, the purpose of this narrative review is to summarize and discuss the available evidence regarding the DASH diet, as well as its components, as it relates to cardiometabolic disease and CKD risk and progression in East Asia.

\section{Characteristics of the DASH Diet and the Original Aim of the DASH Trials}

The original DASH trial was the first study to investigate the effect of consuming an overall healthy dietary pattern on BP using a randomized controlled feeding study [26]. While the control dietary pattern was designed to reflect the usual American diet, the intervention dietary patterns were strategically designed to contain nutrients previously shown to be beneficial for BP reduction. The "ideal" or "combination" dietary pattern, which later became known simply as the DASH diet, emphasized vegetables, fruits, low-fat dairy products, whole grains, fish, poultry, and nuts, and was low in red meat, sweets, and sugar-sweetened beverages [17]. The trial enrolled 459 healthy adults with normal to elevated BP, who followed their assigned diet for eight weeks [26]. The results showed that the DASH diet reduced BP to a greater extent than the control diet and the intermediate "fruits and vegetables" diet. These findings indicate that adopting an overall healthy dietary pattern can effectively reduce BP.

The original DASH trial did not address the effect of sodium intake on BP, as all three study diets contained similar levels of sodium ( 3000 mg/d) [26]. Given the body of evidence suggesting lowering sodium intake may reduce BP, the same research group conducted a second controlled feeding study aimed at investigating the effect of the DASH diet combined with reduced sodium intake on BP [27]. Within the context of the DASH and control (i.e., usual American) dietary patterns, the researchers investigated three different sodium levels: "high" (150 mmol/d or 3500 mg/d), "intermediate" (100 mmol/d or $\sim 2300 \mathrm{mg} / \mathrm{d}$ ), and "low" (50 mmol/d or $1200 \mathrm{mg} / \mathrm{d}$ ) [18]. The trial enrolled 412 adults with elevated BP, who were randomly assigned to one of the two dietary patterns (DASH or control). Participants consumed their assigned dietary pattern at each of the three sodium levels, in randomized order, for 30 days each. The results showed that, within both dietary patterns, lower sodium intake was effective at lowering BP. However, the greatest 
benefit to BP was observed when the DASH diet was combined with lowest sodium intake $(1200 \mathrm{mg} / \mathrm{d})$. Taken together, the findings from both trials suggest that adopting a DASH dietary pattern, especially combined with low sodium intake, is an effective strategy for reducing $\mathrm{BP}$.

\section{The DASH Diet Compared to Usual Dietary Intakes in East Asia}

Since the original trials were published, the DASH diet has been examined and tested in many countries throughout the world with largely positive results. However, because the DASH diet was developed for a U.S. population, it is important to understand how the cultural beliefs and dietary practices of East Asian differ from the U.S. before examining the evidence regarding the DASH diet in this region specifically. For example, in a recent study examining beliefs about healthy diets in young adults in the U.S. and China, participants from both countries agreed on the importance of fruits and vegetables; however, Chinese participants believed meat and foods high in fat and salt should be limited [25]. In addition, Chinese participants in this study emphasized timing of meals, portion sizes, and the types of foods consumed at each eating occasion as factors of a healthy diet. In addition to differences in beliefs regarding food, the U.S. and East Asia differ in the types of foods commonly consumed. Indeed, soy and soy products are regularly consumed in East Asian countries, but are eaten less frequently in the U.S., and evidence suggests this increased consumption of soy products may confer a benefit in terms of chronic disease incidence and mortality [28]. However, Asian diets are becoming increasingly more Westernized, with increased consumption of wheat, high protein and energy-dense foods, potatoes, and dairy, to name a few [29]. All of these dietary factors provide context for understanding how the DASH diet may be adopted and studied in this region.

It is also important to understand how usual dietary intakes in East Asia compare to the original DASH diet guidelines. Comparisons between the DASH diet recommendations $[17,18]$ and usual dietary intakes of adults in major East Asian countries, adapted from Zhang et al. [30], are summarized in Table 1. Nutrient intakes, especially mineral and fiber intakes, are different compared with the DASH diet, which may be partially attributed to increased Westernization of East Asian diets. The traditional Chinese diet has plenty of grains and vegetables [31]. Due in part to economic development and urbanization, Chinese people have shifted from mostly eating at home to now more frequently dining out; as a result, the fast food industry has grown rapidly [32] and fresh vegetable and fiber intakes have decreased in those years [31,33]. Indeed, according to the Global Burden of Disease study, the average intakes of vegetables and fruits in China are $350 \mathrm{~g} / \mathrm{d}$ [34] and $80 \mathrm{~g} / \mathrm{d}$ [12], respectively. In Japan, evidence suggests dietary patterns characterized by plant foods (e.g., fruits and vegetables) and fish have decreased over the past few decades, whereas dietary patterns characterized by high intakes of sugar and red and processed meat have increased [35]. In addition, older Japanese adults tend to adhere more closely to the traditional Japanese diet whereas younger Japanese adults do not, resulting in lower intakes of fruits, vegetables, legumes, fish, and dairy and higher intakes of meats [36]. Though the data are not shown in Table 1, similar trends are observed in South Korea. Indeed, the average sodium intake in South Korea is nearly $4000 \mathrm{mg} / \mathrm{d}$ [37]. In addition, while fruit and vegetable intake has increased over the past several decades, intake of meat and fat has also increased, and intakes of micronutrients such as calcium and potassium remained steady but insufficient [38]. Together, these data suggest that usual dietary intakes in East Asia do not align with DASH diet guidelines. 
Table 1. Comparison between nutrient intakes in the Dietary Approaches to Stop Hypertension (DASH) diet and usual nutrient intakes in selected East Asian countries.

\begin{tabular}{cccc}
\hline Diet Component & DASH & China & Japan \\
\hline Energy intake, kcal & $2100^{1}$ & 2019 & 1913 \\
Protein, \% of energy & 18 & 14.0 & 14.9 \\
Fat, \% of energy & 27 & 36.5 & 25.0 \\
Carbohydrate, \% of energy & 55 & 48.9 & 60.1 \\
Sodium, mg & $1150^{2}$ & 5925 & 4352 \\
Potassium, mg & 4700 & 1691 & 2372 \\
Magnesium, mg & 500 & 275 & 256 \\
Calcium, mg & 1240 & 436 & 522 \\
Fiber, g & 30 & 10.8 & 14.6 \\
\hline
\end{tabular}

${ }^{1}$ Reference range; actual kcal intake for each participant was based on individual needs and characteristics. ${ }^{2}$ Level based on DASH-sodium trial. Abbreviations: DASH, Dietary Approaches to Stop Hypertension.

\section{The DASH Diet and Cardiometabolic Health in East Asia}

As discussed in the previous section, it is important to review the evidence regarding the DASH diet and various health outcomes within specific cultural or regional populations to fully understand its effectiveness. The following sections will review the evidence regarding the relationship between the DASH diet and cardiometabolic health in East Asian populations. The papers reviewed in this section are summarized in Supplemental Table S1.

\subsection{The DASH Diet and Cardiovascular Disease}

The DASH diet was originally developed for a U.S. population; thus, culturallymodified DASH diets have been developed for both Japan [39,40] and South Korea [41,42]. A key feature of both the DASH-Japan Ube Modified diet Program (DASH-JUMP) and the Korean DASH diet (K-DASH) is the incorporation of staple foods, traditional dishes, and other dietary practices from their respective countries into the culturally-modified DASH diet. As with the original DASH trials, the DASH-JUMP diet was investigated in the context of a controlled feeding study, in which participants were provided all food throughout the course of the intervention [39]. Thus, detailed nutrient composition data on the study menus have been published, and are compared to the original DASH diet in Table 2. The original DASH diet and DASH-JUMP have similar nutrient compositions, with the most noticeable difference being the macronutrient distribution and the sodium levels. K-DASH, however, was originally investigated in a free-living context, in which participants were not given food but rather were educated on how to adopt the culturally-modified DASH diet [41]. Thus, detailed study menus and nutrient content for K-DASH have not been reported and could not be included in Table 2.

Both DASH-JUMP and K-DASH have been investigated to determine the effect on CVD risk factors. In the DASH-JUMP study, 58 adults with elevated BP consumed the DASH-JUMP diet for 2 months, then consumed their usual diets for 4 months. The study found that consuming the DASH-JUMP diet resulted in significant decreases in systolic and diastolic BP, which significantly increased after participants returned to their usual dietary intake. The K-DASH diet was originally tested in Korean Americans with elevated BP [41]; the 10-week pilot study found that providing structured education on this culturally adapted DASH diet resulted in significant reductions in ambulatory BP. A later study in Korea explored the effect of an 8-week lifestyle modification intervention, which included the K-DASH diet and exercise, in adults with elevated BP, and observed significant reductions in ambulatory BP [42]. These studies demonstrate the BP benefits of culturally-modified DASH diet interventions in both clinical and free-living settings. However, these studies were relatively short-term. One study from Hong Kong found that providing a one-time counselling session on the DASH diet to patients with newly diagnosed hypertension did not result in significant improvements in cardiovascular risk factors, including blood pressure, BMI, and lipid profile, at 6 or 12 months compared to the 
usual standard of care [43]. The effect of more frequent DASH diet education/counseling on CVD risk in East Asian populations has not been explored.

Table 2. Comparing the original DASH diet to the Japanese DASH diet.

\begin{tabular}{|c|c|c|}
\hline Diet Component & Original DASH & DASH-JUMP (Japan) \\
\hline Energy intake, kcal & $2100^{1}$ & $1820^{3}$ \\
\hline Protein, $\%$ of energy & 18 & 21 \\
\hline Fat, $\%$ of energy & 27 & 18 \\
\hline Carbohydrate, $\%$ of energy & 55 & 61 \\
\hline Sodium, mg & $1150^{2}$ & 3057 \\
\hline Potassium, mg & 4700 & 4333 \\
\hline Magnesium, mg & 500 & 461 \\
\hline Calcium, mg & 1240 & 1242 \\
\hline Fiber, $\mathrm{g}$ & 30 & 28 \\
\hline
\end{tabular}

Rich in:

- Fruits

- Vegetables

- Low-fat dairy

- $\quad$ Fish and lean meats

- Whole grains

Key Characteristics
- Nuts, legumes, seeds

Reduced:

- $\quad$ Saturated fat, total fat, and cholesterol

- $\quad$ Red meat

- $\quad$ Sweets and sweetened beverages

- $\quad$ Refined grains
Rich in:

- Vegetables

- Low-fat dairy

- Whole grain brown rice

- Seaweed

- Mushrooms

Reduced:

- $\quad$ Meat and eggs

- Sweets

- Oils and fats

- Pickles

Other Features:

- Included one meal with soup per day

- Included typical Japanese dishes

\footnotetext{
${ }^{1}$ Reference range; actual kcal intake for each participant was based on individual needs and characteristics. ${ }^{2}$ Level based on DASH-sodium trial. ${ }^{3}$ Also developed a $1650 \mathrm{kcal}$ meal plan. Abbreviations: DASH, Dietary Approaches to Stop Hypertension; DASH-JUMP, DASH-Japan Ube Modified diet Plan.
}

In addition to the intervention studies cited above, observational studies from East Asian countries have explored the link between the DASH diet and CVD. Indeed, a Chinese prospective cohort study found that adopting healthy lifestyle factors, including a DASHstyle diet, was associated with a lower risk of hypertension [44]. Another prospective study in Taiwanese adults found that adherence to a DASH-style diet was inversely associated with change in systolic BP and risk of stroke [45]. When examining the components of the DASH diet, this Taiwanese study also found that both dairy and calcium intake were inversely associated with change in systolic BP. An additional prospective cohort study in Singaporean Chinese adults found that greater adherence to a DASH-style diet was associated with a decreased risk of CVD mortality [46]. In this study, further examination of the DASH diet components found that increased intake of vegetables, fruits, nuts, fiber, and n-3 fatty acids, and decreased intake of red meat were associated with decreased risk of CVD mortality. Additional research from the same cohort study found that greater adherence to the DASH diet was associated with lower risk of coronary artery disease or stroke mortality [47]. Together, these studies suggest DASH diet adherence is inversely associated with CVD risk in East Asian populations.

\subsection{The DASH Diet and Type 2 Diabetes and Other Metabolic Disturbances}

Studies in East Asian populations have also explored the link between the DASH diet and type 2 diabetes. A prospective study using data from the Singapore Chinese Health Study found that greater adherence to a DASH-style diet was associated with a $29 \%$ lower risk of developing type 2 diabetes [48]. One Korean intervention study explored the glycemic benefits of a DASH-style diet [49]. In this study, 60 adults with type 2 diabetes 
were randomly assigned to receive either a DASH-style diet plan with 2 pre-portioned meals per day, a Food Exchange diet plan with 2 pre-portioned meals per day, or a Food Exchange diet plan with no pre-portioned meals for 12 weeks. They observed significant reductions in glycated hemoglobin $(\mathrm{HbA} 1 \mathrm{C})$ in the group assigned to the DASH-style diet compared to the other intervention groups. Together, these studies provide preliminary evidence on the link between the DASH diet and type 2 diabetes risk and management in East Asian populations, though further research is needed.

The relationship between DASH diet adherence and other metabolic disturbances has been explored in East Asian populations. One such disturbance is metabolic syndrome, which is a cluster of factors that are associated with increased risk of cardiometabolic disease, including dyslipidemia, elevated BP, elevated blood glucose, and larger waist circumference [50]. A cross-sectional study using Korean National Health and Nutrition Examination Survey (KNHANES) data found that, in postmenopausal women without diabetes, better adherence to the DASH diet was associated with lower prevalence of metabolic syndrome [51]. Another cross-sectional study using data from the National Health and Nutrition Survey, Japan found that better adherence to the DASH diet was inversely associated with metabolic risk factors including waist circumference, total cholesterol, LDL cholesterol, and BMI [52]. This observational evidence suggests a beneficial effect of the DASH diet for metabolic syndrome, and findings from intervention studies seem to agree $[53,54]$. Indeed, one randomized-controlled trial investigated the effect of an 8-week individualized DASH diet education intervention plus omega-3 fatty acid supplementation on metabolic syndrome parameters in elderly South Korean women [53]. After 8 weeks, DASH diet adherence was significantly higher, and LDL and triglyceride levels were significantly lower in the experimental group, but not in the control group, who only received one DASH diet education session and did not receive omega-3 supplements. Another risk factor for cardiometabolic disease, as well as CKD, is hyperuricemia. Dietary factors are linked to hyperuricemia, and while the evidence is scarce, one observational study from China found that greater adherence to a DASH-style diet is associated with a reduced risk of hyperuricemia [54]. Together, these studies suggest that the DASH diet may be beneficial for metabolic disturbances associated with cardiometabolic disease.

\section{The DASH Diet and Chronic Kidney Disease}

To our knowledge, only one study from East Asia has explored the relationship between the DASH diet and CKD risk. Indeed, a cross-sectional study using KNHANES data found that elderly adults with greater adherence to a DASH-style diet had lower odds of having CKD [55]. In addition, as mentioned in the previous section, a study from China found that adherence to a DASH-style diet is associated with a reduced risk of hyperuricemia, which itself is a risk factor for CKD [54]. No study from East Asia has explored the relationship between the DASH diet and CKD progression or CKD-related complications.

Previous reviews from other countries have acknowledged that recommending the DASH dietary pattern in CKD is controversial due to concerns regarding protein, potassium, and phosphorus intake, particularly in advanced CKD [56]. Therefore, closer examination of the components of the DASH diet (i.e., specific nutrients or food groups emphasized in the DASH diet) may be warranted to explore strategies for developing a modified DASH diet for individuals with CKD. As discussed previously, the DASH dietary pattern was carefully designed to increase nutrients considered to be beneficial for BP (i.e., calcium, potassium, magnesium, protein, and fiber), and to limit nutrients thought to negatively affect BP (i.e., sodium and saturated fat) [26,27]. When translated into foods, the DASH diet emphasizes the intake of fruits and vegetables; low-fat dairy products; whole grains; lean meat, poultry, and fish; and nuts, seeds, and legumes, and minimizes the intake of full-fat dairy; high-fat meats; and products with added sugars [57]. Below, we review the evidence regarding the relationships between DASH diet components and CKD risk and 
CKD complications in East Asian populations. The papers reviewed in this section are summarized in Supplemental Table S1.

\subsection{DASH Diet Components and the Risk of Developing CKD}

Minerals, particularly sodium and potassium, are important components of the DASH dietary pattern. In the DASH diet, sodium intake is limited due to the well-documented effects of excess sodium intake on BP and CVD risk [27]. Given that hypertension is the most common underlying etiology for CKD [6], sodium intake is an important consideration for CKD risk. A prospective cohort study from South Korea found that, in participants with hypertension, both low and high sodium intakes were associated with an increased risk of developing CKD [58]. However, in participants without hypertension, there was no difference in CKD risk based on sodium intake level. These findings may suggest that sodium intake is a risk factor for CKD in those who are already at increased risk of developing CKD, though clinical studies are needed to confirm this. The only intervention study from East Asia examining sodium reduction and CKD risk comes from an 18-month cluster-randomized trial in China [59]. In this study, 120 villages were randomized to receive either a sodium reduction program, which included community health education and providing access to a potassium-based salt substitute, or the control. They found that, compared to control, participants in the sodium reduction program had lower urinary albumin-to-creatinine ratio and lower odds of albuminuria, both of which are indicators of kidney function [59]. Contrary to sodium, potassium intake is emphasized in the DASH diet. A prospective cohort study in South Korean adults with impaired kidney function found that a higher potassium intake was associated with a decreased risk of CKD development and less estimated glomerular filtration rate (eGFR) decline, but only in participants with hypertension [60]. These findings are corroborated by a cross-sectional study from South Korea, which found that low potassium intake was associated with increased odds of advanced stage CKD, though only in participants with hypertension [61]. Phosphorus, though not included in the DASH diet guidelines, is another mineral that may be higher in this diet due to increased intakes of dairy, whole grains, and lean protein sources. The same cross-sectional study from South Korea also examined phosphorus intake and similarly found that lower phosphorus intake was associated with increased risk of advanced stage CKD in participants with hypertension [61]. It should be noted that dietary guidance typically recommends that patients with CKD reduce their intakes of potassium and phosphorus in order to avoid CKD progression and further complications. Further research, including clinical evidence, is needed to determine potassium and phosphorus recommendations for patients at risk of CKD, particularly in the context of a DASH-style dietary pattern.

Other nutrients and food groups that are emphasized in the DASH diet may have implications for CKD risk. Fruits and vegetables are an important part of the DASH diet, and evidence suggests that they could be beneficial for preventing CKD. A South Korean prospective cohort study found that, in participants with normal kidney function at baseline, a diet rich in fruits and vegetables was associated with a decreased risk of incident CKD and proteinuria [62]. This study found that a diet high in fruits and vegetables had a lower dietary acid load, as assessed by estimated net endogenous acid production (eNEAP), and postulate this may contribute to the reduction in CKD risk [62]. The eNEAP is a calculated ratio of dietary protein to potassium; higher potassium intake results in a lower eNEAP, and higher protein intake results in a higher eNEAP. As with potassium and phosphorus, dietary guidelines recommend patients with CKD reduce their protein intake. One cross-sectional study from Japan found that higher protein (total, animal, vegetable) intake was associated with a higher GFR in both men and women, and a lower risk of CKD in women [63]. While these results suggest that higher protein intake may be protective against CKD, these results should be interpreted with caution, as they may be influenced by reverse causality (i.e., patients reduce their protein intake after being diagnosed with CKD upon recommendations from their doctor). The source of protein, especially different 
animal proteins, could also play a role in CKD risk. A prospective cohort study of a Chinese population in Singapore found that consumption of red meat, which tends to be higher in saturated fat, was positively associated with end-stage kidney disease (ESKD); however, no such association was found between leaner sources of protein, including fish, eggs, and poultry, with ESKD risk [64]. Further research is needed to fully elucidate the relationship between individual DASH diet components and CKD risk in an East Asian population.

\subsection{The DASH Diet and Its Components in Diagnosed CKD}

To our knowledge, no study from East Asia has investigated the DASH diet in patients who already have CKD. However, studies have explored the effect of components of the DASH diet, including minerals, fruits, and vegetables, in patients with CKD. As discussed previously, reducing sodium intake can help lower BP and ultimately reduce CKD risk. In those who already have CKD, reducing sodium intake seems to help with lowering $\mathrm{BP}$ and slowing the progression of kidney damage. A cross-sectional study in South Korean patients with all stages of CKD found that those with lower 24-h urinary sodium excretion, an indicator of sodium intake, more often achieved appropriate BP control [65]. An intervention study from China similarly found that lower sodium intake was associated with a higher rate of BP control in patients with non-dialysis hypertensive CKD [66]. This Chinese publication also included a small dietary sodium restriction study conducted at the same clinic, which found that a 7-day sodium restriction intervention in patients with immunoglobulin A nephropathy (IgAN) resulted in a significant decrease in BP as well as proteinuria [66]. Together, these findings suggest that reducing sodium intake in patients with CKD may help to achieve BP control and reduce kidney damage. However, as one Chinese study found, reducing sodium intake may be difficult for patients with non-dialysis dependent CKD [67]. While most patients in this study indicated they were aware of the need to restrict dietary sodium, reported barriers to achieving dietary sodium reduction largely included a lack of knowledge, especially regarding condiment use in cooking. This suggests that East Asian patients with CKD could benefit from reducing their sodium intake, though more public health efforts are needed to help these patients make dietary changes.

Other mineral components of the DASH diet are important to consider in terms of CKD progression. While potassium is associated with CKD prevention, the effect of potassium intake in patients with CKD is controversial, as hyperkalemia is a concern in these patients. However, evidence on the effect of potassium reduction in CKD is mixed. A South Korean cohort study in patients with non-dialysis CKD stages 1-5 found that lower urinary potassium excretion, an indicator of potassium intake, is associated with a higher risk of CKD progression, defined as a $\geq 50 \%$ decrease in eGFR and onset of ESKD [68]. A separate South Korean cohort study in patients with non-dialysis CKD stages $1-5$ found that a higher urinary $\mathrm{Na} / \mathrm{K}$ ratio (i.e., relatively higher sodium intake and relatively lower potassium intake) was associated with a greater risk of renal outcomes, defined as a 50\% reduction in eGFR or initiation of renal replacement therapy [69]. Together, these studies suggest that a higher potassium intake may be beneficial for East Asians with CKD. However, more evidence is needed to truly understand the risks and benefits of potassium intake in patients with CKD, especially in patients with advanced CKD. Magnesium is another mineral emphasized in the DASH diet because of the demonstrated inverse relationship between magnesium intake and BP [26]. One randomized controlled trial in Japanese patients with CKD stages 3-4 examined the effect of 2 years of magnesium oxide supplementation on coronary artery calcification, which is a risk factor cardiovascular events and mortality in CKD [70]. They found that supplementation of magnesium oxide resulted in significantly lower coronary artery calcification progression compared to the control group. These findings suggest that the effect of increased magnesium intake on cardiovascular complications in East Asians with CKD warrants further investigation.

Vegetables and fruits are emphasized in the DASH diet; however, CKD dietary guidance often recommends lower intakes of certain fruits and vegetables in order to reduce 
potassium intake. The recommendation to reduce fruit and vegetable intake in CKD has been met with controversy, mainly due to the large amount of additional health benefits that come with eating a diet rich in fruits and vegetables. One observational study in Japanese pre-dialysis CKD patients found that higher NEAP, a risk factor for CKD progression, was associated with lower intakes of fruits and vegetables, and greater NEAP was associated with greater reductions in eGFR [71]. Fruits and vegetables are also high in fiber, which may be beneficial for patients with CKD. One longitudinal study in Chinese adults with CKD stages 3-4 found that increased fiber intake was associated with a smaller decrease in eGFR when compared to a lower fiber intake $(<25 \mathrm{~g} / \mathrm{d})$, suggesting a higher fiber (>25 g/d) intake may slow the progression of CKD in this population [72]. While these studies provide preliminary evidence that consuming more fruits and vegetables may be beneficial in East Asian patients with CKD, more research is needed to fully explore the effects of a fruit- and vegetable-rich diet, such as the DASH diet, on CKD progression and complications in this population.

To our knowledge, there are no studies that have examined other DASH diet components, such as whole grains and low-fat dairy, in East Asian patients with CKD. These food groups are rich in potassium, phosphorus, and protein, three nutrients of concern in patients with CKD. Indeed, review papers from non-Asian countries have indicated that higher intakes of these nutrients may preclude recommending the DASH diet for patients with CKD if they have already experienced metabolic complications, or if their medication regimen increases their risk of metabolic complications [73]. However, whole grains are also important sources of fiber and magnesium, and low-fat dairy also provides magnesium as well as calcium. Excess calcium is a concern in CKD; however, both positive and negative calcium balance may lead to poor health outcomes in CKD patients (soft tissue calcification and loss of bone mineral, respectively), especially as it relates to CKD-mineral bone disorder (CKD-MBD) [74]. Additional studies, especially intervention studies, are needed to examine other DASH diet components in East Asians with CKD.

\subsection{Comparing the DASH Diet with East Asian and International CKD Dietary Guidelines}

Many countries, including China and Japan, have developed clinical guidelines for diagnosing, treating, and managing CKD based on the best available evidence. These guidelines include dietary recommendations for relevant nutrients including protein, lipids, carbohydrate, sodium, potassium, phosphorus, calcium, and fiber. CKD dietary guidelines from China [75], Japan [76], and the International Kidney Disease: Improving Global Outcomes (KDIGO) [77] guidelines, and the diet composition of the DASH diet [17,18] are summarized in Table 3. The DASH diet guideline for protein falls within the Acceptable Macronutrient Distribution Range set by the Institute of Medicine (now called the National Academy of Medicine), which also established a Recommended Dietary Allowance of $0.8 \mathrm{~g} / \mathrm{kg}$ body weight/day [78]. This aligns with the recommendations for early-stage CKD from all three guidelines, which do not yet recommend reductions in protein intake. However, both Chinese and Japanese CKD dietary guidelines recommend reductions in protein intake for more advanced stages of CKD. For other macronutrients, the DASH diet guidelines align well with all three CKD dietary guidelines. Notably, besides protein, sodium is the only other nutrient with explicit intake recommendations in all three CKD dietary guidelines. The sodium recommendations of all three CKD dietary guidelines are similar, and the DASH diet guidelines for sodium fall well below these recommendations. Other nutrients of concern in CKD are potassium, phosphorus, and calcium. None of the CKD dietary guidelines provide explicit recommendations for potassium intake; both China and Japan provide recommendations based on serum potassium levels, and KDIGO states potassium intake recommendations should be individualized. The recommended potassium intake in the DASH diet is $4700 \mathrm{mg} / \mathrm{d}$, which is higher than usual intakes in East Asia (see Table 1). In addition, phosphorus intake recommendations are inconsistent among the three CKD dietary guidelines: China recommends $<800 \mathrm{mg} / \mathrm{d}$, Japan recommends normal phosphorus intakes, and KDIGO recommends individualized intake guidelines. 
The DASH diet does not provide phosphorus intake guidelines, though some of the food groups recommended as part of the DASH diet are high in phosphorus. Calcium recommendations in CKD are also mixed: China recommends $\leq 2000 \mathrm{mg} / \mathrm{d}$, Japan recommends normal calcium intakes, and KDIGO does not provide a recommendation for calcium. The DASH dietary guidelines recommend $1240 \mathrm{mg} / \mathrm{d}$ of calcium, which aligns with the CKD dietary guidelines from China. When comparing the DASH diet with CKD dietary guidelines in East Asia and globally, it seems the DASH diet could be recommended in early stages of $\mathrm{CKD}$, based on individualized needs, with caution and careful monitoring for metabolic complications, a sentiment that has been echoed by others [73]. 
Table 3. Comparison of the DASH diet to global and East Asian chronic kidney disease (CKD) dietary guidelines ${ }^{1}$.

\begin{tabular}{|c|c|c|c|c|c|c|}
\hline \multirow[b]{2}{*}{$\begin{array}{c}\text { Dietary } \\
\text { Component }\end{array}$} & \multirow[b]{2}{*}{ DASH Dietary Pattern } & \multicolumn{3}{|c|}{ East Asian Dietary Guidelines by CKD Stage } & \multicolumn{2}{|c|}{ International Guidelines by CKD Stage } \\
\hline & & CKD Stage & China & Japan & CKD Stage & Global (KDIGO) \\
\hline Protein & $18 \%$ of energy & $\begin{array}{c}\text { G1-2 } \\
\text { G3-5 non-dialysis } \\
\text { G3-5 dialysis }\end{array}$ & $\begin{array}{l}0.8-1.0 \mathrm{~g} / \mathrm{kg} \times \mathrm{SBW} / \mathrm{d} \\
0.6-0.8 \mathrm{~g} / \mathrm{kg} \times \mathrm{SBW} / \mathrm{d} \\
1.0-1.2 \mathrm{~g} / \mathrm{kg} \times \mathrm{SBW} / \mathrm{d}\end{array}$ & $\begin{array}{l}0.8-1.0 \mathrm{~g} / \mathrm{kg} \times \mathrm{SBW} / \mathrm{d} \\
0.6-0.8 \mathrm{~g} / \mathrm{kg} \times \mathrm{SBW} / \mathrm{d}\end{array}$ & $\begin{array}{c}\text { GFR }<30 \mathrm{~mL} / \mathrm{min} \\
(\mathrm{G} 4-5)\end{array}$ & $0.8 \mathrm{~g} / \mathrm{kg} / \mathrm{d}$ \\
\hline Lipids & $27 \%$ of energy & $\mathrm{G} 1-5$ & $25-35 \%$ & None & - & None \\
\hline Carbohydrate & $55 \%$ of energy & G1-5 & $55-65 \%$ & None & - & None \\
\hline Sodium & $11,150^{1}$ & G1-5 & $<2000 \mathrm{mg} / \mathrm{d}$ & $\begin{array}{c}\text { Salt } 6 \mathrm{~g} / \mathrm{d}(2400 \mathrm{mg} \text { of } \\
\text { sodium })\end{array}$ & G1-5 & $<2000 \mathrm{mg} /$ day \\
\hline Potassium & 4700 & G1-5 & $\begin{array}{l}\text { Limited when patient } \\
\text { has hyperkalemia }\end{array}$ & $4.0-5.4 \mathrm{mEq} / \mathrm{L}^{2}$ & - & $\begin{array}{l}\text { Recommendation should be } \\
\text { tailored to CKD severity and } \\
\text { individual needs }\end{array}$ \\
\hline Phosphorus & - & G1-5 & $<800 \mathrm{mg} / \mathrm{d}$ & Normal range & - & $\begin{array}{l}\text { Recommendation should be } \\
\text { tailored to CKD severity and } \\
\text { individual needs }\end{array}$ \\
\hline Calcium & 1240 & G1-5 & $\leq 2000 \mathrm{mg} / \mathrm{d}$ & Normal range & - & None \\
\hline Fiber & 30 & G1-5 & $14 \mathrm{~g} / 1000 \mathrm{kcal}$ & None & - & None \\
\hline
\end{tabular}

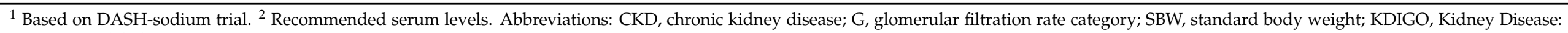
Improving Global Outcomes. 


\section{Discussion}

The current review is a narrative review and not a systematic review, and is therefore limited in the conclusions that can be drawn from the summarized evidence. In addition, there are limitations in the available literature on the DASH diet and chronic disease in East Asian populations. Notably, more observational studies than intervention studies have been conducted in the East Asian population regarding the DASH diet and cardiometabolic health and CKD. A wider body of evidence on the DASH diet and chronic disease has come from research in Western countries, particularly the U.S., and the results are largely positive [79-82]. One could infer this relationship would hold true in East Asia, but additional studies are needed to confirm that the benefits of the DASH diet are truly translatable to this population. Cardiometabolic diseases as well as CKD are highly prevalent in East Asian countries. These diseases share many underlying risk factors, particularly elevated BP. It is well known that hypertension is a significant modifiable risk factor for CVD and CKD, and adequate BP control can considerably decrease the risk of cardiovascular events, diabetic nephropathy, and CKD progression. Diet is an important modifiable risk factor for these chronic diseases, and evidence indicates that adopting an overall healthy dietary pattern can be a valuable strategy to alleviate the burden of these diseases. Evidence in East Asian populations indicates that adopting a DASH diet may protect against cardiometabolic disease development and progression. Evidence suggests the DASH diet may also be protective against CKD development. When examining individual food groups and nutrients that are emphasized in the DASH dietary pattern, evidence from East Asian populations suggests that eating fruits and vegetables (which provide potassium, magnesium, and fiber), low-fat dairy products (which provide calcium, potassium, magnesium, and phosphorus), and lean protein (which also provides potassium, magnesium, and phosphorus) may help reduce the risk of developing CKD, but the benefits of these foods/nutrients in those who already have CKD is controversial and at odds with many of the typical food/nutrient restrictions recommended for CKD patients. The DASH diet limits sodium intake, and research in East Asian populations suggests that reducing sodium intake is beneficial both for preventing CKD and reducing CKD complications. Whether or not the DASH diet, or a modified version of the DASH diet, should be recommended for patients with CKD remains unclear. More research, especially randomized controlled trials, on the potential benefits of adopting a modified DASH diet in East Asian patients with CKD is needed. Additional evidence in populations who already have, or are at risk for, CKD and cardiometabolic diseases could help inform dietary guidelines as well as clinical practice in East Asian countries.

Supplementary Materials: The following are available online at https:/ / www.mdpi.com/2072-664 3/13/3/984/s1, Table S1: Summary of Studies Reviewed on the DASH Diet and Cardiometabolic Diseases and CKD1.

Author Contributions: Conceptualization, Y.S., A.J.L., Y.W. and K.M.H.G.; investigation, Y.S. and A.J.L.; resources, K.M.H.G.; writing—original draft preparation, Y.S. and A.J.L.; writing—review and editing, Y.S., A.J.L., Y.W. and K.M.H.G.; visualization, Y.S. and A.J.L.; supervision, A.J.L. and K.M.H.G.; project administration, A.J.L. and K.M.H.G.; funding acquisition, A.J.L. and K.M.H.G. All authors have read and agreed to the published version of the manuscript.

Funding: This research was partially funded by a predoctoral fellowship from the Indiana Clinical and Translational Sciences Institute, which is funded by the National Center for Advancing Translational Sciences, Clinical and Translational Science Awards, grant \# UL1TR002529 and grant \# TL1TR002531 as well as the National Institute of Diabetes and Digestive and Kidney Diseases, grant \#K01DK102864.

Conflicts of Interest: The authors declare no conflict of interest. The funders had no role in the design of the study; in the collection, analyses, or interpretation of data; in the writing of the manuscript, or in the decision to publish the results. 


\section{References}

1. Jha, V.; Garcia-Garcia, G.; Iseki, K.; Li, Z.; Naicker, S.; Plattner, B.; Saran, R.; Wang, A.Y.; Yang, C.W. Chronic kidney disease: Global dimension and perspectives. Lancet 2013, 382, 260-272. [CrossRef]

2. Saklayen, M.G. The Global Epidemic of the Metabolic Syndrome. Curr. Hypertens. Rep. 2018, 20, 12. [CrossRef] [PubMed]

3. Ma, L.Y.; Chen, W.W.; Gao, R.L.; Liu, L.S.; Zhu, M.L.; Wang, Y.J.; Wu, Z.S.; Li, H.J.; Gu, D.F.; Yang, Y.J.; et al. China cardiovascular diseases report 2018: An updated summary. J. Geriatr. Cardiol. 2020, 17, 1-8. [CrossRef]

4. Guariguata, L.; Whiting, D.R.; Hambleton, I.; Beagley, J.; Linnenkamp, U.; Shaw, J.E. Global estimates of diabetes prevalence for 2013 and projections for 2035. Diabetes Res. Clin. Pract. 2014, 103, 137-149. [CrossRef]

5. Wu, A.Y.T.; Kong, N.C.T.; de Leon, F.A.; Pan, C.Y.; Tai, T.Y.; Yeung, V.T.F.; Yoo, S.J.; Rouillon, A.; Weir, M.R. An alarmingly high prevalence of diabetic nephropathy in Asian type 2 diabetic patients: The MicroAlbuminuria Prevalence (MAP) Study. Diabetologia 2005, 48, 17-26. [CrossRef] [PubMed]

6. Taler, S.J.; Agarwal, R.; Bakris, G.L.; Flynn, J.T.; Nilsson, P.M.; Rahman, M.; Sanders, P.W.; Textor, S.C.; Weir, M.R.; Townsend, R.R. KDOQI US commentary on the 2012 KDIGO clinical practice guideline for management of blood pressure in CKD. Am. J. Kidney Dis. 2013, 62, 201-213. [CrossRef]

7. Yan, Z.; Wang, Y.; Li, S.; Wang, J.; Zhang, L.; Tan, H.; Li, S.; Yang, L.; Pei, H.; Zhang, L.; et al. Hypertension Control in Adults with CKD in China: Baseline Results from the Chinese Cohort Study of Chronic Kidney Disease (C-STRIDE). Am. J. Hypertens. 2017, 31, 486-494. [CrossRef]

8. Wang, J.; Zhang, L.; Tang, S.C.; Kashihara, N.; Kim, Y.S.; Togtokh, A.; Yang, C.W.; Zhao, M.H.; Board, E.A.R. Disease burden and challenges of chronic kidney disease in North and East Asia. Kidney Int. 2018, 94, 22-25. [CrossRef] [PubMed]

9. Eknoyan, G.; Lameire, N.; Barsoum, R.; Eckardt, K.U.; Levin, A.; Levin, N.; Locatelli, F.; MacLeod, A.; Vanholder, R.; Walker, R.; et al. The burden of kidney disease: Improving global outcomes. Kidney Int. 2004, 66, 1310-1314. [CrossRef] [PubMed]

10. Zhang, L.; Wang, F.; Wang, L.; Wang, W.; Liu, B.; Liu, J.; Chen, M.; He, Q.; Liao, Y.; Yu, X.; et al. Prevalence of chronic kidney disease in China: A cross-sectional survey. Lancet 2012, 379, 815-822. [CrossRef]

11. Zhang, L.; Zhao, M.H.; Zuo, L.; Wang, Y.; Yu, F.; Zhang, H.; Wang, H.; Group, C.-N.W. China Kidney Disease Network (CK-NET) 2015 Annual Data Report. Kidney Int. Suppl. 2019, 9, e1-e81. [CrossRef]

12. Collaborators, G.D. Health effects of dietary risks in 195 countries, 1990-2017: A systematic analysis for the Global Burden of Disease Study 2017. Lancet 2019, 393, 1958-1972. [CrossRef]

13. Zhao, L.; Stamler, J.; Yan, L.L.; Zhou, B.; Wu, Y.; Liu, K.; Daviglus, M.L.; Dennis, B.H.; Elliott, P.; Ueshima, H.; et al. Blood pressure differences between northern and southern Chinese: Role of dietary factors: The International Study on Macronutrients and Blood Pressure. Hypertension 2004, 43, 1332-1337. [CrossRef]

14. Kesteloot, H.; Park, B.C.; Lee, C.S.; Brems-Heyns, E.; Claessens, J.; Joossens, J.V. A comparative study of blood pressure and sodium intake in Belgium and in Korea. Eur. J. Cardiol. 1980, 11, 169-182.

15. Sougawa, Y.; Miyai, N.; Morioka, I.; Utsumi, M.; Takeda, S.; Miyashita, K.; Arita, M. The combination of obesity and high salt intake are associated with blood pressure elevation among healthy Japanese adolescents. J. Hum. Hypertens. 2020, $34,117-124$. [CrossRef]

16. Stamler, J.; Chan, Q.; Daviglus, M.L.; Dyer, A.R.; Van Horn, L.; Garside, D.B.; Miura, K.; Wu, Y.; Ueshima, H.; Zhao, L.; et al. Relation of Dietary Sodium (Salt) to Blood Pressure and Its Possible Modulation by Other Dietary Factors: The INTERMAP Study. Hypertension 2018, 71, 631-637. [CrossRef]

17. Appel, L.J.; Moore, T.J.; Obarzanek, E.; Vollmer, W.M.; Svetkey, L.P.; Sacks, F.M.; Bray, G.A.; Vogt, T.M.; Cutler, J.A.; Windhauser, M.M.; et al. A clinical trial of the effects of dietary patterns on blood pressure. DASH Collaborative Research Group. N. Engl. J. Med. 1997, 336, 1117-1124. [CrossRef]

18. Sacks, F.M.; Svetkey, L.P.; Vollmer, W.M.; Appel, L.J.; Bray, G.A.; Harsha, D.; Obarzanek, E.; Conlin, P.R.; Miller, E.R., III; SimonsMorton, D.G.; et al. Effects on blood pressure of reduced dietary sodium and the Dietary Approaches to Stop Hypertension (DASH) diet. DASH-Sodium Collaborative Research Group. N. Engl. J. Med. 2001, 344, 3-10. [CrossRef]

19. Harnden, K.E.; Frayn, K.N.; Hodson, L. Dietary Approaches to Stop Hypertension (DASH) diet: Applicability and acceptability to a UK population. J. Hum. Nutr. Diet. 2010, 23, 3-10. [CrossRef]

20. Paula, T.P.; Viana, L.V.; Neto, A.T.Z.; Leitão, C.B.; Gross, J.L.; Azevedo, M.J. Effects of the DASH Diet and Walking on Blood Pressure in Patients with Type 2 Diabetes and Uncontrolled Hypertension: A Randomized Controlled Trial. J. Clin. Hypertens. 2015, 17, 895-901. [CrossRef]

21. Azadbakht, L.; Mirmiran, P.; Esmaillzadeh, A.; Azizi, T.; Azizi, F. Beneficial effects of a Dietary Approaches to Stop Hypertension eating plan on features of the metabolic syndrome. Diabetes Care 2005, 28, 2823-2831. [CrossRef]

22. Nowson, C.A.; Wattanapenpaiboon, N.; Pachett, A. Low-sodium Dietary Approaches to Stop Hypertension-type diet including lean red meat lowers blood pressure in postmenopausal women. Nutr. Res. 2009, 29, 8-18. [CrossRef]

23. Koley, M.; Mundle, M.; Ghosh, S.; Saha, S. A short-term pilot study investigating the efficacy of DASH diet in reducing systolic and/or diastolic blood pressure in patients with essential hypertension. Asian J. Pharm. Clin. Res. 2013, 6, 169-172.

24. Ma, R.C.W.; Chan, J.C.N. Type 2 diabetes in East Asians: Similarities and differences with populations in Europe and the United States. Ann. N. Y. Acad. Sci. 2013, 1281, 64-91. [CrossRef] [PubMed]

25. Banna, J.C.; Gilliland, B.; Keefe, M.; Zheng, D. Cross-cultural comparison of perspectives on healthy eating among Chinese and American undergraduate students. BMC Public Health 2016, 16, 1015. [CrossRef] 
26. Sacks, F.M.; Obarzanek, E.; Windhauser, M.M.; Svetkey, L.P.; Vollmer, W.M.; McCullough, M.; Karanja, N.; Lin, P.H.; Steele, P.; Proschan, M.A. Rationale and design of the Dietary Approaches to Stop Hypertension trial (DASH). A multicenter controlledfeeding study of dietary patterns to lower blood pressure. Ann. Epidemiol. 1995, 5, 108-118. [CrossRef]

27. Svetkey, L.P.; Sacks, F.M.; Obarzanek, E.; Vollmer, W.M.; Appel, L.J.; Lin, P.H.; Karanja, N.M.; Harsha, D.W.; Bray, G.A.; Aickin, M.; et al. The DASH Diet, Sodium Intake and Blood Pressure Trial (DASH-sodium): Rationale and design. DASH-Sodium Collaborative Research Group. J. Am. Diet. Assoc. 1999, 99, S96-S104. [CrossRef]

28. He, F.-J.; Chen, J.-Q. Consumption of soybean, soy foods, soy isoflavones and breast cancer incidence: Differences between Chinese women and women in Western countries and possible mechanisms. Food Sci. Hum. Wellness 2013, 2, 146-161. [CrossRef]

29. Pingali, P. Westernization of Asian diets and the transformation of food systems: Implications for research and policy. Food Policy 2007, 32, 281-298. [CrossRef]

30. Zhang, R.; Wang, Z.; Fei, Y.; Zhou, B.; Zheng, S.; Wang, L.; Huang, L.; Jiang, S.; Liu, Z.; Jiang, J.; et al. The Difference in Nutrient Intakes between Chinese and Mediterranean, Japanese and American Diets. Nutrients 2015, 7, 4661-4688. [CrossRef]

31. Wang, H.J.; Wang, Z.H.; Zhang, J.G.; Du, W.W.; Su, C.; Zhang, J.; Zhai, F.Y.; Zhang, B. Trends in dietary fiber intake in Chinese aged 45 years and above, 1991-2011. Eur. J. Clin. Nutr. 2014, 68, 619-622. [CrossRef]

32. Du, W.; Su, C.; Wang, H.; Wang, Z.; Wang, Y.; Zhang, B. Is density of neighbourhood restaurants associated with BMI in rural Chinese adults? A longitudinal study from the China Health and Nutrition Survey. BMJ Open 2014, 4, e004528. [CrossRef] [PubMed]

33. Guo, Q.Y.; Zhao, L.Y.; He, Y.N.; Fang, Y.H.; Fang, H.Y.; Xu, X.L.; Jia, F.M.; Yu, D.M. Survey on dietary nutrients intake of Chinese residents between 2010 and 2012. Zhonghua Yu Fang Yi Xue Za Zhi 2017, 51, 519-522. [CrossRef] [PubMed]

34. Li, Y.C.; Jiang, B.; Zhang, M.; Huang, Z.J.; Deng, Q.; Zhou, M.G.; Zhao, Z.P.; Wang, Y.F.; Wang, L.M. Vegetable and Fruit Consumption among Chinese Adults and Associated Factors: A Nationally Representative Study of 170,847 Adults. Biomed. Environ. Sci. 2017, 30, 863-874. [CrossRef]

35. Murakami, K.; Livingstone, M.B.E.; Sasaki, S. Thirteen-Year Trends in Dietary Patterns among Japanese Adults in the National Health and Nutrition Survey 2003-2015: Continuous Westernization of the Japanese Diet. Nutrients 2018, 10, 994. [CrossRef]

36. Yokoyama, Y.; Sasaki, M.; Sato, K. Nutrition intake among the Japanese elderly: An intergenerational comparison based on national health and nutrition survey scores. Ann. Hum. Biol. 2019, 46, 311-322. [CrossRef]

37. Park, H.-K.; Lee, Y.; Kang, B.-W.; Kwon, K.-I.; Kim, J.-W.; Kwon, O.-S.; Cobb, L.K.; Campbell, N.R.C.; Blakeman, D.E.; Kim, C.-I. Progress on sodium reduction in South Korea. BMJ Glob. Health 2020, 5, e002028. [CrossRef] [PubMed]

38. Kim, J.-G.; Kim, J.-S.; Kim, J.G. Trends of Food Supply and Nutrient Intake in South Korea over the Past 30 Years. Curr. Res. Nutr. Food Sci. J. 2019, 7, 85-95. [CrossRef]

39. Kawamura, A.; Kajiya, K.; Kishi, H.; Inagaki, J.; Mitarai, M.; Oda, H.; Umemoto, S.; Kobayashi, S. Effects of the DASH-JUMP dietary intervention in Japanese participants with high-normal blood pressure and stage 1 hypertension: An open-label single-arm trial. Hypertens. Res. 2016, 39, 777-785. [CrossRef]

40. Kawamura, A.; Kajiya, K.; Kishi, H.; Inagaki, J.; Mitarai, M.; Oda, H.; Umemoto, S.; Kobayashi, S. The Nutritional Characteristics of the Hypotensive WASHOKU-modified DASH Diet: A Sub-analysis of the DASH-JUMP Study. Curr. Hypertens. Rev. 2018, 14, 56-65. [CrossRef] [PubMed]

41. Kim, H.; Song, H.J.; Han, H.R.; Kim, K.B.; Kim, M.T. Translation and validation of the dietary approaches to stop hypertension for koreans intervention: Culturally tailored dietary guidelines for Korean Americans with high blood pressure. J. Cardiovasc. Nurs. 2013, 28, 514-523. [CrossRef]

42. Lee, C.J.; Kim, J.Y.; Shim, E.; Hong, S.H.; Lee, M.; Jeon, J.Y.; Park, S. The Effects of Diet Alone or in Combination with Exercise in Patients with Prehypertension and Hypertension: A Randomized Controlled Trial. Korean Circ. J. 2018, 48, 637-651. [CrossRef] [PubMed]

43. Wong, M.C.; Wang, H.H.; Kwan, M.W.; Fong, B.C.; Chan, W.M.; Zhang, D.X.; Li, S.T.; Yan, B.P.; Coats, A.J.; Griffiths, S.M. Dietary counselling has no effect on cardiovascular risk factors among Chinese Grade 1 hypertensive patients: A randomized controlled trial. Eur. Heart J. 2015, 36, 2598-2607. [CrossRef]

44. Bai, G.; Zhang, J.; Zhao, C.; Wang, Y.; Qi, Y.; Zhang, B. Adherence to a healthy lifestyle and a DASH-style diet and risk of hypertension in Chinese individuals. Hypertens. Res. 2017, 40, 196-202. [CrossRef]

45. Lin, P.H.; Yeh, W.T.; Svetkey, L.P.; Chuang, S.Y.; Chang, Y.C.; Wang, C.; Pan, W.H. Dietary intakes consistent with the DASH dietary pattern reduce blood pressure increase with age and risk for stroke in a Chinese population. Asia Pac. J. Clin. Nutr. 2013, 22, 482-491.

46. Neelakantan, N.; Koh, W.P.; Yuan, J.M.; van Dam, R.M. Diet-Quality Indexes Are Associated with a Lower Risk of Cardiovascular, Respiratory, and All-Cause Mortality among Chinese Adults. J. Nutr. 2018, 148, 1323-1332. [CrossRef] [PubMed]

47. Talaei, M.; Koh, W.P.; Yuan, J.M.; van Dam, R.M. DASH Dietary Pattern, Mediation by Mineral Intakes, and the Risk of Coronary Artery Disease and Stroke Mortality. J. Am. Heart Assoc. 2019, 8, e011054. [CrossRef]

48. Chen, G.C.; Koh, W.P.; Neelakantan, N.; Yuan, J.M.; Qin, L.Q.; van Dam, R.M. Diet Quality Indices and Risk of Type 2 Diabetes Mellitus: The Singapore Chinese Health Study. Am. J. Epidemiol. 2018, 187, 2651-2661. [CrossRef]

49. Jin, S.-M.; Ahn, J.; Park, J.; Hur, K.Y.; Kim, J.H.; Lee, M.-K. East Asian diet-mimicking diet plan based on the Mediterranean diet and the Dietary Approaches to Stop Hypertension diet in adults with type 2 diabetes: A randomized controlled trial. J. Diabetes Investig. 2020. [CrossRef] 
50. Grundy, S.M.; Cleeman, J.I.; Daniels, S.R.; Donato, K.A.; Eckel, R.H.; Franklin, B.A.; Gordon, D.J.; Krauss, R.M.; Savage, P.J.; Smith, S.C.; et al. Diagnosis and management of the metabolic syndrome: An American Heart Association/National Heart, Lung, and Blood Institute Scientific Statement. Circulation 2005, 112, 2735-2752. [CrossRef]

51. Kang, S.H.; Cho, K.H.; Do, J.Y. Association between the Modified Dietary Approaches to Stop Hypertension and Metabolic Syndrome in Postmenopausal Women without Diabetes. Metab. Syndr. Relat. Disord. 2018, 16, 282-289. [CrossRef]

52. Murakami, K.; Livingstone, M.B.E.; Sasaki, S. Diet quality scores in relation to metabolic risk factors in Japanese adults: A cross-sectional analysis from the 2012 National Health and Nutrition Survey, Japan. Eur. J. Nutr. 2019, 58, 2037-2050. [CrossRef]

53. Choi, S.H.; Choi-Kwon, S. The effects of the DASH diet education program with omega-3 fatty acid supplementation on metabolic syndrome parameters in elderly women with abdominal obesity. Nutr. Res. Pr. 2015, 9, 150-157. [CrossRef]

54. Gao, Y.; Cui, L.F.; Sun, Y.Y.; Yang, W.H.; Wang, J.R.; Wu, S.L.; Gao, X. Adherence to the Dietary Approaches to Stop Hypertension (DASH) diet and hyperuricemia: A Cross-sectional Study. Arthritis Care Res. 2020. [CrossRef]

55. Lee, H.S.; Lee, K.B.; Hyun, Y.Y.; Chang, Y.; Ryu, S.; Choi, Y. DASH dietary pattern and chronic kidney disease in elderly Korean adults. Eur. J. Clin. Nutr. 2017, 71, 755-761. [CrossRef]

56. Banerjee, T.; Liu, Y.; Crews, D.C. Dietary Patterns and CKD Progression. Blood Purif. 2016, 41, 117-122. [CrossRef] [PubMed]

57. Campbell, A.P. DASH Eating Plan: An Eating Pattern for Diabetes Management. Diabetes Spectr. 2017, 30, 76-81. [CrossRef] [PubMed]

58. Yoon, C.Y.; Noh, J.; Lee, J.; Kee, Y.K.; Seo, C.; Lee, M.; Cha, M.U.; Kim, H.; Park, S.; Yun, H.R.; et al. High and low sodium intakes are associated with incident chronic kidney disease in patients with normal renal function and hypertension. Kidney Int. 2018, 93, 921-931. [CrossRef]

59. Jardine, M.J.; Li, N.; Ninomiya, T.; Feng, X.; Zhang, J.; Shi, J.; Zhang, Y.; Zhang, R.; Hao, J.; Perkovic, V.; et al. Dietary Sodium Reduction Reduces Albuminuria: A Cluster Randomized Trial. J. Ren. Nutr. 2019, 29, 276-284. [CrossRef]

60. Mun, K.H.; Yu, G.I.; Choi, B.Y.; Kim, M.K.; Shin, M.H.; Shin, D.H. Association of Dietary Potassium Intake with the Development of Chronic Kidney Disease and Renal Function in Patients with Mildly Decreased Kidney Function: The Korean Multi-Rural Communities Cohort Study. Med. Sci. Monit. 2019, 25, 1061-1070. [CrossRef]

61. Kim, J.; Lee, J.; Kim, K.N.; Oh, K.H.; Ahn, C.; Kang, D.; Park, S.K. Association between Dietary Mineral Intake and Chronic Kidney Disease: The Health Examinees (HEXA) Study. Int. J. Environ. Res. Public Health 2018, 15, 1070. [CrossRef] [PubMed]

62. Jhee, J.H.; Kee, Y.K.; Park, J.T.; Chang, T.I.; Kang, E.W.; Yoo, T.H.; Kang, S.W.; Han, S.H. A Diet Rich in Vegetables and Fruit and Incident CKD: A Community-Based Prospective Cohort Study. Am. J. Kidney Dis. 2019, 74, 491-500. [CrossRef] [PubMed]

63. Higashiyama, A.; Watanabe, M.; Kokubo, Y.; Ono, Y.; Okayama, A.; Okamura, T.; Group, N.D.R. Relationships between protein intake and renal function in a Japanese general population: NIPPON DATA90. J. Epidemiol. 2010, 20 (Suppl. 3), S537-S543. [CrossRef]

64. Lew, Q.J.; Jafar, T.H.; Koh, H.W.; Jin, A.; Chow, K.Y.; Yuan, J.M.; Koh, W.P. Red Meat Intake and Risk of ESRD. J. Am. Soc. Nephrol. 2017, 28, 304-312. [CrossRef]

65. Koo, H.S.; Kim, Y.C.; Ahn, S.Y.; Oh, S.W.; Kim, S.; Chin, H.J. Analysis of correlation between 24-hour urinary sodium and the degree of blood pressure control in patients with chronic kidney disease and non-chronic kidney disease. J. Korean Med. Sci. 2014, 29 (Suppl. 2), S117-S122. [CrossRef] [PubMed]

66. Yu, W.; Luying, S.; Haiyan, W.; Xiaomei, L. Importance and benefits of dietary sodium restriction in the management of chronic kidney disease patients: Experience from a single Chinese center. Int. Urol. Nephrol. 2012, 44, 549-556. [CrossRef]

67. Wang, Y.; Yu, F.; Bao, Y.; Zhang, L.; Wang, H. Factors impacting sodium restriction in patients with chronic kidney disease: A cohort study from a Chinese center. Int. Urol. Nephrol. 2016, 48, 745-749. [CrossRef]

68. Kim, H.W.; Park, J.T.; Yoo, T.H.; Lee, J.; Chung, W.; Lee, K.B.; Chae, D.W.; Ahn, C.; Kang, S.W.; Choi, K.H.; et al. Urinary Potassium Excretion and Progression of CKD. Clin. J. Am. Soc. Nephrol. 2019, 14, 330-340. [CrossRef]

69. Koo, H.; Hwang, S.; Kim, T.H.; Kang, S.W.; Oh, K.H.; Ahn, C.; Kim, Y.H. The ratio of urinary sodium and potassium and chronic kidney disease progression: Results from the KoreaN Cohort Study for Outcomes in Patients with Chronic Kidney Disease (KNOW-CKD). Medicine 2018, 97, e12820. [CrossRef]

70. Sakaguchi, Y.; Hamano, T.; Obi, Y.; Monden, C.; Oka, T.; Yamaguchi, S.; Matsui, I.; Hashimoto, N.; Matsumoto, A.; Shimada, K.; et al. A Randomized Trial of Magnesium Oxide and Oral Carbon Adsorbent for Coronary Artery Calcification in Predialysis CKD. J. Am. Soc. Nephrol. 2019, 30, 1073-1085. [CrossRef]

71. Toba, K.; Hosojima, M.; Kabasawa, H.; Kuwahara, S.; Murayama, T.; Yamamoto-Kabasawa, K.; Kaseda, R.; Wada, E.; Watanabe, R.; Tanabe, N.; et al. Higher estimated net endogenous acid production with lower intake of fruits and vegetables based on a dietary survey is associated with the progression of chronic kidney disease. BMC Nephrol. 2019, 20, 421. [CrossRef] [PubMed]

72. Lu, L.; Huang, Y.F.; Wang, M.Q.; Chen, D.X.; Wan, H.; Wei, L.B.; Xiao, W. Dietary fiber intake is associated with chronic kidney disease (CKD) progression and cardiovascular risk, but not protein nutritional status, in adults with CKD. Asia Pac. J. Clin. Nutr. 2017, 26, 598-605. [CrossRef]

73. Tyson, C.C.; Nwankwo, C.; Lin, P.H.; Svetkey, L.P. The Dietary Approaches to Stop Hypertension (DASH) eating pattern in special populations. Curr. Hypertens. Rep. 2012, 14, 388-396. [CrossRef]

74. Hill Gallant, K.M.; Spiegel, D.M. Calcium Balance in Chronic Kidney Disease. Curr. Osteoporos. Rep. 2017, 15, 214-221. [CrossRef] [PubMed] 
75. National Health and Family Planning Commission of China. Dietary Guide for Chronic Kidney Disease Patients. In Chinese Health Industry Standard; National Health and Family Planning Commission of China: Beijing, China, 2017.

76. Japanese Society of Nephrology. Dietary recommendations for chronic kidney disease, 2014. Nihon Jinzo Gakkai Shi 2014, 56, 553-599.

77. Kidney International Supplements. Chapter 3: Management of progression and complications of CKD. Kidney Int. Suppl. 2013, 3, 73-90. [CrossRef]

78. Institute of Medicine. Dietary Reference Intakes for Energy, Carbohydrate, Fiber, Fat, Fatty Acids, Cholesterol, Protein, and Amino Acids; The National Academies Press: Washington, DC, USA, 2005. [CrossRef]

79. Mozaffari, H.; Ajabshir, S.; Alizadeh, S. Dietary Approaches to Stop Hypertension and risk of chronic kidney disease: A systematic review and meta-analysis of observational studies. Clin. Nutr. 2020, 39, 2035-2044. [CrossRef] [PubMed]

80. Chiavaroli, L.; Viguiliouk, E.; Nishi, S.K.; Blanco Mejia, S.; Rahelić, D.; Kahleová, H.; Salas-Salvadó, J.; Kendall, C.W.; Sievenpiper, J.L. DASH Dietary Pattern and Cardiometabolic Outcomes: An Umbrella Review of Systematic Reviews and Meta-Analyses. Nutrients 2019, 11, 338. [CrossRef]

81. Siervo, M.; Lara, J.; Chowdhury, S.; Ashor, A.; Oggioni, C.; Mathers, J.C. Effects of the Dietary Approach to Stop Hypertension (DASH) diet on cardiovascular risk factors: A systematic review and meta-analysis. Br. J. Nutr. 2015, 113, 1-15. [CrossRef]

82. Shirani, F.; Salehi-Abargouei, A.; Azadbakht, L. Effects of Dietary Approaches to Stop Hypertension (DASH) diet on some risk for developing type 2 diabetes: A systematic review and meta-analysis on controlled clinical trials. Nutrition 2013, 29, 939-947. [CrossRef] 